\title{
Insufficient health care access in American minorities with or at high risk for knee osteoarthritis: Data from the Osteoarthritis Initiative
}

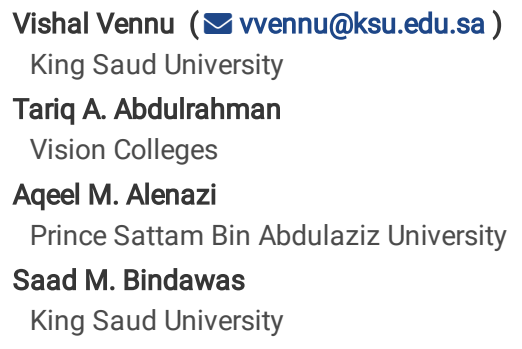




\section{Abstract}

Background: Access to health care $(\mathrm{HC})$ in American minorities with or at high risk for knee osteoarthritis (OA) is indistinct. The current study aims to address this gap.

Methods: Data of Americans ( $n=4,674)$ aged 45-79 years with or at elevated risk for knee OA were fetched from the Osteoarthritis Initiative. Participants were categorized into Caucasians and American minorities based on their racial and ethnic background.

Results: American minorities had insufficient access to $\mathrm{HC}$ than did Caucasians ( $9 \%$ vs. $2 \%$ were uninsured with no health care coverage (HCC), $p<.0001$, while $6 \%$ vs. $9 \%$ had only HCC, $p<.0001$ ). A multinomial regression analysis shows that less than $<50,000$ American dollar annual income was more likely associated with insufficient access to $\mathrm{HC}$ (odds ratio $[\mathrm{OR}]=3.82,95 \%$ confidence interval $[\mathrm{Cl}]=2.25-6.51$ ) in American minorities than Caucasians $(\mathrm{OR}=$ $1.93,95 \% \mathrm{Cl}=1.50-2.48)$.

Conclusion: American minorities had insufficient access to $\mathrm{HC}$ than did Caucasians. The less annual income was highly influenced by insufficient access to $\mathrm{HC}$ in this population.

\section{Background}

A 17-member commission of experts from the Institute of Medicine (IOM) in the United States specified access to health care (HC) as a "timely use of personal health services to achieve the best possible health outcomes" [1]. This committee was chosen for the Access Monitoring Project to develop a set of indicators to monitor access to personal $\mathrm{HC}$ services at the national level over time. The commission believes that no or inadequate health care coverage (HCC) is one of the signs of failure to obtain timely and appropriate care, which makes a difference in the state of one's health. Insufficient health insurance and low incomes are probably more common among American minorities-such as African Americans, Asians, and other non-whites-than among Caucasians. These differences have been steadily growing over the past two decades due to the increased prevalence and incidence of chronic diseases [1].

However, chronic conditions like osteoarthritis $(\mathrm{OA})$, particularly knee $O A$, which induces significant long-term pain and disability, are one of the reasons many people use medical care [2]. Usually, knee OA is not self-limiting, but its prevalence in the United States has continued to increase over the past several decades along with the aging population and the growing obesity epidemic that is expected to be the fourth leading reason of disability by 2020 [3, 4]. It accelerates a significant economic burden that increases the lifetime cost of patients with knee OA from onset until death who undergo total knee arthroplasty (TKA) [5], which is an expensive procedure [6]. In addition, adverse consequences can occur after TKA if regular medical care is absent [7]. Thus, access to $\mathrm{HC}$ can donate to enhance functioning after TKA in a patient with knee OA and can minimize disability even when life cannot be extended [1].

Racial and ethnic disparities in those with onset or at high risk of knee OA have been significant and persistent in the United States [3]. American minorities are more likely to suffer from knee OA than Caucasians [3]. However, the rate of TKA is higher in Caucasians than among American minorities [8]. As a result, one of the Healthy People 2020 objectives call for emerging issues in access to health services to be addressed [1].

Around 20 million adults have gained health insurance coverage over the first half of this decade because of the Patient Protection and Affordable Care Act of 2010 [9]. However, millions of Americans still lack coverage [10]. Having both a regular source of care and insurance are essential indicators of access to $\mathrm{HC}$ [11]. However, studies have been reported that the presence of a usual source of concern more critical in predicting access to HC than insurance status [12]. Data from the Healthy People Midcourse Review also demonstrate that uninsured American minorities fare worse than uninsured Caucasians in obtaining access to $\mathrm{HC}$, which corresponds with a previous report [13]. This may be attributed to the fact that American minorities are less likely to have a regular source of care than do Caucasians [14]. A review provides compelling evidence from the findings of four studies showing that health insurance accounts for much of the variation in racial and ethnic differences in access to a regular source of care [14]. These disparities endure with all levels of passage to $\mathrm{HC}$, including health and dental insurance, having an ongoing source of care, and access to primary care.

The noted influence from the studies mentioned above on access to $\mathrm{HC}$ in American minorities with or at high risk for knee OA is vague. Thus, the present study aims to address this limitation in the literature by comparing Caucasians who had the same condition. The hypothesis is that there would be insufficient access to $\mathrm{HC}$ in American minorities with or at high risk for knee OA compared to Caucasians.

\section{Methods}

A secondary analysis was performed using data from the Osteoarthritis Initiative (OAI). The OAI is a publicly and privately funded multicenter, longitudinal study to examine the onset and progression of knee OA. A total of 4,796 participants in the OAl study were recruited from four clinical sites in the United States (US) (Baltimore, Maryland; Pittsburgh, Pennsylvania; Pawtucket, Rhode Island; and Columbus, Ohio) between February 2004 and May 2006. An overview of the OAI is provided elsewhere [15]. The Institutional Review Board of the University of California (Coordinating Center), San Francisco has approved the OAI protocol. Each participant was instructed about the objectives and procedures of the study by the investigator at each site. All the participants were provided with informed consent forms, which they signed before enrollment in the OAl study.

In the present cross-sectional study, data of 4,674 participants aged 45-79 years with or at high risk for knee OA were included. Based on the racial and ethnic background, all participants were classified as Caucasians and American minorities, such as African Americans, Asians, and other non-whites. Participants $(n=122)$ who had no pain, aching, or stiffness in either knee in the past year; no radiographic finding of OA; and no eligibility risk factor of $O A$ were excluded from the analysis. 
Access to $\mathrm{HC}$ was defined by asking the self-reported question: "Where do you usually go for health care or advice about your health care?" Answers included "private doctor," "public clinic," "health maintenance organization (HMO)," "hospital clinic," "emergency room," and "other." Similar questions were posed in the 2001-2003 Medicare Current Beneficiaries Survey and the 2002 Area Resource File [16]. The HCC statuses of participants were determined by asking the selfreported question: "Do you currently have any kind of health care coverage?" The answers to this question included private health insurance (such as Blue Cross), prepaid plans (such as those of Health Maintenance Organizations [HMOs]), and Preferred Provider Organizations (PPOs) or any governmentsponsored plans such as Medicare, Medicaid, or Veterans' Affairs (VA) coverage. Participants' insurance statuses were determined by asking the self-reported question: "Do you have any health insurance plan that pays for all or part of the cost of prescription medicines?" Similar questions were posed in a previous study [17]. Based on the presence or absence of HCC and insurance, access to HC has been classified into four levels: 1) presence of both HCC and insurance, 2) presence of $\mathrm{HCC}$ and absence of insurance, 3) the absence of $\mathrm{HCC}$ and presence of insurance, and 4) absence of both HCC and insurance.

Participants' sociodemographic and smoking status, as well as body mass index (BMI), were collected. Based on self-reports, participants' gender (male or female), household composition (living alone or with others), and income per year in United States dollars $(<50,000$ or $\geq 50,000)$ were also recorded. Education was categorized into three levels: primary school or less, college graduate, and graduate or beyond. Age was used as continuous to show the age difference and also stratified by a five-year gap $(<50,50-54,55-59,60-64$, and $\geq 65)$ to show the presence or absence of HCC and insurance between both groups. Data on marital (married and unmarried/divorced/widow) and smoking (none- and current or former smoker) status were included. BMI was calculated using participants' measured weight in kilograms divided by height in square meters. According to the World Health Organization [18], BMI was classified into three levels: normal weight (18.5-24.9), overweight (25-29.9), and obese (30 or above).

The sample characteristics were described using means and standard deviation (SD) for the continuous variables and frequencies for the categorical variables. The significant difference between Caucasians and American minorities was determined by utilizing a t-test for the continuous variables and a chisquare test for the categorical variables. For Caucasians and American minorities, the distribution of sociodemographic data by age group, gender, educational level, income per year, household composition, marital status, smoking status, and BMI according to the presence and absence of HCC and insurance were provided in the count (percentages). The significance between the sociodemographic, HCC, and insurance statuses was examined using a chisquare test in both groups. A multinomial regression model was used to identify the factors behind insufficient access to HC in Caucasians and American minorities. All the analyses were performed using the Statistical Analysis Software (SAS) for Windows version 9.4 (SAS Institute, Inc., Cary, NC, US).

\section{Results}

Table 1 shows the sociodemographic characteristics of all, Caucasians, and American minorities. Of the 4,674 participants, 79\% were Caucasians ( $n=3,677$ ), and $21 \%$ were American minorities ( $n=997)$ with an average age of 60.5 years. American minorities were three years younger than Caucasians. Women of American minorities (68\% of all the participants) formed the dominant gender, and most participants (57\%) had lower annual incomes. The majority of Caucasians were married (72\%), living with a spouse or other family members (80\%), and with a greater HCC (98\%). Most of the American minorities were current smokers $(13 \%)$ and obese $\left(\mathrm{BMl}>30 \mathrm{~kg} / \mathrm{m}^{2}\right)$. Most of the Caucasians had both $\mathrm{HCC}$ and insurance ( $\left.89 \%\right)$ with a private doctor as an $\mathrm{HC}$ provider (89\%). 
Table 1

The sociodemographic characteristics of all the study sample, Caucasians, and American minorities

\begin{tabular}{|c|c|c|c|c|}
\hline Characteristics & $\begin{array}{l}\text { All } \\
n=4,674\end{array}$ & $\begin{array}{l}\text { Caucasians } \\
n=3,677(79 \%)\end{array}$ & $\begin{array}{l}\text { American minorities } \\
n=997(21 \%)\end{array}$ & P-value \\
\hline Age (years), mean (SD) & $60.5(9)$ & $61.9(9.3)$ & $59.1(8.4)$ & $<.0001$ \\
\hline Age groups & & & & $<.0001$ \\
\hline$<50$ & $511(12.5)$ & $388(12.1)$ & $123(14.2)$ & \\
\hline $50-54$ & $123(3)$ & $81(2.5)$ & $42(4.8)$ & \\
\hline $55-59$ & 847 (20.7) & $615(19.2)$ & $232(26.8)$ & \\
\hline $60-64$ & $891(19.4)$ & $600(18.7)$ & $191(22.1)$ & \\
\hline$\geq 65$ & $1803(44.4)$ & $1525(47.5)$ & $278(32.1)$ & \\
\hline Gender & & & & $<.0001$ \\
\hline Men & $1,945(42)$ & $1625(44)$ & $320(32)$ & \\
\hline Women & $2,729(58)$ & $2052(56)$ & $677(68)$ & \\
\hline Education & & & & $<.0001$ \\
\hline Primary school or less & $770(16)$ & $493(13)$ & $277(28)$ & \\
\hline College graduate & $2101(45)$ & $1628(44)$ & $473(47)$ & \\
\hline Some graduate & $1803(39)$ & $1556(43)$ & $247(25)$ & \\
\hline The income per year, USD & & & & $<.0001$ \\
\hline$<50,000$ & $1758(38)$ & $1193(32)$ & $566(57)$ & \\
\hline$\geq 50,000$ & $2916(62)$ & $2484(68)$ & $432(43)$ & \\
\hline Marital status & & & & $<.0001$ \\
\hline Married & $3078(65.8)$ & $2663(72.4)$ & $415(41.6)$ & \\
\hline Unmarried/divorced/widow & $1596(34.2)$ & $1014(27.6)$ & $582(58.4)$ & \\
\hline Smoking status & & & & $<.0001$ \\
\hline Nonsmoker & 4359 (93.3) & $3495(95)$ & $864(86.7)$ & \\
\hline Current or former smoker & $315(7)$ & $182(5)$ & $133(13)$ & \\
\hline Household composition & & & & $<.0001$ \\
\hline Single & $1043(22)$ & $723(20)$ & $320(32)$ & \\
\hline With others & $3631(78)$ & $2954(80)$ & $677(68)$ & \\
\hline Body mass index (BMI), kg/m² & & & & $<.0001$ \\
\hline Normal weight (18.5-24.9) & $1068(22.9)$ & $950(25.9)$ & $118(11.9)$ & \\
\hline Overweight (25-29.9) & $1832(39.3)$ & $1508(41.1)$ & $324(32.7)$ & \\
\hline Obese $(\geq 30)$ & $1761(37.8)$ & $1211(33)$ & $550(55.4)$ & \\
\hline Access to health care factors & & & & $<.0001$ \\
\hline HCC \& insurance present & $4018(87)$ & $3218(89)$ & $800(83)$ & \\
\hline HCC present \& insurance absent & $412(9)$ & $350(9)$ & $62(7)$ & \\
\hline HCC absent \& insurance present & $13(0.3)$ & $3(0.08)$ & $10(1)$ & \\
\hline HCC \& insurance absent & $153(3.3)$ & $65(1.8)$ & $88(9)$ & \\
\hline Health care provider & & & & $<.0001$ \\
\hline Private doctor & $3907(84)$ & $3277(89)$ & $630(63)$ & \\
\hline Public clinic & $131(3)$ & $50(2)$ & $81(8)$ & \\
\hline
\end{tabular}

SOURCE Authors' analysis of baseline data from Osteoarthritis Initiative, 2004-6. NOTES There were statistically significant differences in all sociodemographic characteristics between Caucasians and American minorities. HCC, health care coverage; HMO, health maintenance organization; BMI, body mass index; USD=the United States dollars. Values are present mean (SD) or $n(\%)$. 


\begin{tabular}{|llll|}
\hline Characteristics & All & Caucasians & American minorities \\
\hline HMO & $n=4,674$ & $n=3,677(79 \%)$ & P-value \\
\hline Hospital clinic & $318(7)$ & $196(5)$ & $71(7)$ \\
\hline Emergency room & $114(2)$ & $43(1)$ & $19(2)$ \\
\hline Others & $31(0.6)$ & $12(0.3)$ & $74(8)$ \\
\hline $\begin{array}{l}\text { SOURCE Authors' analysis of baseline data from Osteoarthritis Initiative, 2004-6. NOTES There were statistically significant differences in all } \\
\text { sociodemographic characteristics between Caucasians and American minorities. HCC, health care coverage; HMO, health maintenance organization; BMI, } \\
\text { body mass index; USD=the United States dollars. Values are present mean (SD) or n (\%). }\end{array}$ \\
\hline
\end{tabular}

Table 2 presents the distribution of sociodemographic status according to the presence or absence of HCC and insurance in Caucasians and American minorities. Among all participants, access to HC (presence or absence of HCC and insurance) was significantly associated with age, education, annual income, and marital and current smoking statuses. In terms of access to $\mathrm{HC}$, there were significant differences between Caucasians and American minorities. The majority of Caucasians aged 65 years and above (38\%) had both HCC and insurance for access to HC ( $p<.0001)$, while only $28 \%$ of American minorities of a similar age had both $\mathrm{HCC}$ and insurance for access to $\mathrm{HC}(p<.0001)$. There were significant differences between Caucasians and American minorities in terms of sociodemographic characteristics, as well. American minorities who had both HCC and insurance for access to HC ( $p<.0001)$ had lower education $(41 \%)$, and annual income (43\%), and fewer were married (38\%) compared to Caucasians $(p<.0001)$ who had higher education (39\%) and annual income $(63 \%)$ and most of whom were married (66\%). There were also significant differences in terms of those who smoked and lived at home. Most American minorities $(p=0.003)$ were current smokers $(10 \%)$, while only $56 \%$ of them were living with family members compared to Caucasians $(p<.0001)$ among whom there were fewer current smokers $(4 \%)$, with $72 \%$ of them living with family members. 
Table 2

Distribution of sociodemographic characteristics according to the presence or absence of health care coverage and insurance in Caucasians and American minorities

\begin{tabular}{|c|c|c|c|c|c|c|c|c|c|c|}
\hline \multirow[t]{4}{*}{ Variable } & \multicolumn{5}{|c|}{ Caucasians $(n=3677)$} & \multicolumn{5}{|c|}{ American minorities $(n=997)$} \\
\hline & \multicolumn{10}{|c|}{ Health care coverage status, $n$ \% } \\
\hline & $\begin{array}{l}\text { Present } \\
\text { both HCC } \\
\& \\
\text { Insurance }\end{array}$ & $\begin{array}{l}\text { Present } \\
\text { HCC \& } \\
\text { Insurance } \\
\text { absent }\end{array}$ & $\begin{array}{l}\text { HCC } \\
\text { absent \& } \\
\text { Insurance } \\
\text { present }\end{array}$ & $\begin{array}{l}\text { Both HCC } \\
\& \\
\text { Insurance } \\
\text { absent }\end{array}$ & $\begin{array}{l}\mathrm{P}- \\
\text { value }\end{array}$ & $\begin{array}{l}\text { Present } \\
\text { both HCC } \\
\& \\
\text { Insurance }\end{array}$ & $\begin{array}{l}\text { Present } \\
\text { HCC \& } \\
\text { Insurance } \\
\text { absent }\end{array}$ & $\begin{array}{l}\text { HCC } \\
\text { absent \& } \\
\text { Insurance } \\
\text { present }\end{array}$ & $\begin{array}{l}\text { Both HCC } \\
\& \\
\text { Insurance } \\
\text { absent }\end{array}$ & $\begin{array}{l}\mathrm{P}- \\
\text { value }\end{array}$ \\
\hline & $\begin{array}{l}(n= \\
2,775)\end{array}$ & $(n=338)$ & $(n=3)$ & $(n=56)$ & & $(n=693)$ & $(n=56)$ & $(n=8)$ & $(n=75)$ & \\
\hline \multicolumn{5}{|l|}{ Age in years } & \multirow[t]{6}{*}{$<.0001$} & & & & & \multirow[t]{6}{*}{$<.0001$} \\
\hline$<50$ & $388(12)$ & $16(0.5)$ & $1(0.03)$ & $12(0.4)$ & & $93(11)$ & $6(0.7)$ & $1(0.1)$ & $19(2)$ & \\
\hline $50-54$ & 78 (3) & $4(0.1)$ & $0(0.0)$ & $2(0.06)$ & & $28(3.3)$ & $1(0.1)$ & $1(0.1)$ & $8(0.9)$ & \\
\hline $55-59$ & $592(18)$ & $18(0.5)$ & $1(0.03)$ & $25(0.8)$ & & $180(21)$ & $12(0.4)$ & $3(0.4)$ & $31(4)$ & \\
\hline $60-64$ & $565(17)$ & $29(0.9)$ & $1(0.03)$ & $18(0.5)$ & & $161(19)$ & $8(0.9)$ & $3(0.4)$ & $15(2)$ & \\
\hline$\geq 65$ & $1251(38)$ & $275(8)$ & $0(0.0)$ & $0(0.0)$ & & $238(28)$ & $29(3)$ & $0(0.0)$ & $3(0.3)$ & \\
\hline \multicolumn{5}{|l|}{ Gender } & \multirow[t]{3}{*}{0.32} & & & & & \multirow[t]{3}{*}{0.55} \\
\hline Men & $1466(39)$ & $143(3.8)$ & $2(0.05)$ & $32(0.85)$ & & $256(26)$ & $19(2)$ & $5(0.5)$ & $32(3.3)$ & \\
\hline Women & $1858(56)$ & $211(5.6)$ & $1(0.03)$ & $34(0.91)$ & & $551(57)$ & $43(5)$ & $5(0.5)$ & $57(6)$ & \\
\hline \multicolumn{5}{|l|}{ Education } & \multirow[t]{4}{*}{$<.0001$} & & & & & \multirow[t]{4}{*}{0.0002} \\
\hline Primary school or less & $420(11)$ & $53(1.4)$ & $1(0.03)$ & $18(0.48)$ & & $202(21)$ & $29(3)$ & $6(0.6)$ & $33(3.4)$ & \\
\hline College graduate & $1444(38)$ & $180(4.8)$ & $2(0.05)$ & $30(0.8)$ & & $402(41)$ & $24(2)$ & $4(0.4)$ & $42(4.3)$ & \\
\hline Some graduate & 1460 (39) & $121(3.2)$ & $0(0.0)$ & $18(0.5)$ & & $203(21)$ & $9(0.9)$ & $0(0.0)$ & $14(1.4)$ & \\
\hline \multicolumn{5}{|l|}{ The income per year } & \multirow[t]{3}{*}{$<.0001$} & & & & & \multirow[t]{3}{*}{$<.0001$} \\
\hline$<\$ 50,000$ & $976(26)$ & $164(4.3)$ & $2(0.05)$ & $52(1.4)$ & & $422(43)$ & $49(5)$ & $8(0.8)$ & $80(8)$ & \\
\hline$>\$ 50,000$ & $2348(63)$ & $190(5)$ & $1(0.03)$ & $14(0.4)$ & & $385(40)$ & $13(1.3)$ & $2(0.2)$ & $9(0.9)$ & \\
\hline \multicolumn{11}{|l|}{ Marital status } \\
\hline Married & $2386(66)$ & $240(6.6)$ & $2(0.06)$ & $21(0.6)$ & \multirow[t]{2}{*}{$<.0001$} & $368(38)$ & $20(2)$ & $2(0.2)$ & $20(2)$ & \multirow[t]{2}{*}{$<.0001$} \\
\hline Unmarried/divorced/widow & $\begin{array}{l}832 \\
(22.9)\end{array}$ & $110(3)$ & $1(0.03)$ & $44(1.2)$ & & $432(45)$ & $42(4.4)$ & $8(0.8)$ & $68(7)$ & \\
\hline \multicolumn{11}{|l|}{ Smoking status } \\
\hline None smoker & $\begin{array}{l}3067 \\
(84.3)\end{array}$ & $340(9.3)$ & $3(0.08)$ & $50(1.4)$ & \multirow[t]{2}{*}{$<.0001$} & $\begin{array}{l}704 \\
(73.3)\end{array}$ & $55(5.7)$ & $8(0.8)$ & $63(6.6)$ & \multirow[t]{2}{*}{0.0003} \\
\hline Current or former smoker & $157(4)$ & $10(0.2)$ & $0(0.0)$ & $15(0.4)$ & & $96(10)$ & $7(0.7)$ & $2(0.2)$ & $25(2)$ & \\
\hline \multicolumn{5}{|l|}{ Household composition } & \multirow[t]{3}{*}{$<.0001$} & & & & & \multirow[t]{3}{*}{0.92} \\
\hline Single & $608(16)$ & $91(2)$ & $0(0.0)$ & $27(0.7)$ & & $262(27)$ & $22(2)$ & $4(0.4)$ & $29(3)$ & \\
\hline With others & $2716(72)$ & $263(7)$ & $3(0.08)$ & $39(1.0)$ & & $545(56)$ & $40(4)$ & $6(0.6)$ & $60(6)$ & \\
\hline \multicolumn{11}{|l|}{$\begin{array}{l}\text { Body mass index (BMI), } \\
\mathrm{kg} / \mathrm{m}^{2}\end{array}$} \\
\hline Normal weight (18.5-24.9) & $\begin{array}{l}828 \\
(22.8)\end{array}$ & $92(2.5)$ & $0(0.0)$ & $17(0.47)$ & \multirow[t]{3}{*}{0.095} & $94(9.8)$ & $9(0.9)$ & $1(0.10)$ & $11(1.1)$ & 0.533 \\
\hline Overweight (25-29.9) & $\begin{array}{l}1320 \\
(36.4)\end{array}$ & $153(4.2)$ & $2(0.06)$ & $17(0.47)$ & & $\begin{array}{l}273 \\
(28.6)\end{array}$ & $17(1.8)$ & $3(0.31)$ & $21(2.2)$ & \\
\hline Obese $(\geq 30)$ & $\begin{array}{l}1063 \\
(33.1)\end{array}$ & $104(2.9)$ & $1(0.03)$ & $31(0.85)$ & & $\begin{array}{l}429 \\
(44.9)\end{array}$ & $35(3.7)$ & $6(0.63)$ & $56(5.9)$ & \\
\hline $\begin{array}{l}\text { SOURCE Authors' analysis of } \\
\text { of sociodemographic charac } \\
\text { except gender (Caucasians, } \\
\text { mass index }\end{array}$ & $\begin{array}{l}\text { aseline dat } \\
\text { ristics acco } \\
0.34 \text { and } A\end{array}$ & $\begin{array}{l}\text { from Osteo } \\
\text { ding to the } p \\
\text { herican minc }\end{array}$ & $\begin{array}{l}\text { thritis Initia } \\
\text { sence or ab } \\
\text { ties, } p=0.5\end{array}$ & $\begin{array}{l}\text { le, } 2004-6 . \\
\text { ence of heal } \\
\text {. HCC, Healt }\end{array}$ & $\begin{array}{l}\text { DTES Th } \\
\text { h care co } \\
\text { care cov }\end{array}$ & $\begin{array}{l}\text { e were statis } \\
\text { erage and in } \\
\text { rage; } \mathrm{HMO}, \mathrm{l}\end{array}$ & $\begin{array}{l}\text { ically signif } \\
\text { urance in C } \\
\text { alth mainte }\end{array}$ & $\begin{array}{l}\text { ant differen } \\
\text { Icasians an } \\
\text { ance organi }\end{array}$ & $\begin{array}{l}\text { s in the dis } \\
\text { American r } \\
\text { ation; BMI, }\end{array}$ & $\begin{array}{l}\text { bution } \\
\text { רorities, } \\
\text { dy }\end{array}$ \\
\hline
\end{tabular}


Table 3 shows factors associated with more insufficient access to $\mathrm{HC}$ in Caucasians and American minorities. In American minorities, less than $<50,000$ American dollar income per annum was more likely associated significantly with insufficient access to $\mathrm{HC}$ (odds ratio [OR] $=3.82,95 \%$ confidence interval [Cl] $=2.25-6.51)$ compared with Caucasians $(\mathrm{OR}=1.93,95 \% \mathrm{Cl}=1.50-2.48)$. Other factors, such as age 65 years or above and current or former smoking status were more likely associated significantly with insufficient access to $\mathrm{HC}$ among Caucasians $(\mathrm{OR}=2.34,95 \% \mathrm{Cl}=1.52-3.62 ; \mathrm{OR}=1.58,95 \% \mathrm{Cl}=1.00-2.50$, respectively), whereas unmarried/divorced/widow status was associated significantly among American minorities $(\mathrm{OR}=2.19,95 \% \mathrm{Cl}=1.33-3.62)$.

Table 3

Factors associated with more inadequate access to health care in Caucasians and American minorities with or at high risk for knee osteoarthritis

\begin{tabular}{|c|c|c|c|c|}
\hline \multirow[t]{2}{*}{ Variable } & \multicolumn{2}{|l|}{ Caucasians } & \multicolumn{2}{|c|}{ American minorities } \\
\hline & OR $(95 \% \mathrm{Cl})$ & P-value & OR $(95 \% \mathrm{Cl})$ & P-value \\
\hline \multicolumn{5}{|l|}{ Age in years } \\
\hline$<50$ & 1.00 & & 1.00 & \\
\hline $50-54$ & $1.01(0.40-2.52)$ & 0.983 & $1.69(0.69-4.11)$ & 0.246 \\
\hline $55-59$ & $0.99(0.61-1.61)$ & 0.963 & $1.01(0.56-1.80)$ & 0.976 \\
\hline $60-64$ & $1.05(0.65-1.71)$ & 0.842 & $0.53(0.28-1.02)$ & 0.057 \\
\hline$\geq 65$ & $2.34(1.52-3.62)$ & 0.0001 & $0.37(0.19-0.73)$ & 0.059 \\
\hline \multicolumn{5}{|l|}{ Gender } \\
\hline Men & 1.00 & & 1.00 & \\
\hline Women & $0.88(0.69-1.11)$ & 0.274 & $0.69(0.45-1.05)$ & 0.084 \\
\hline \multicolumn{5}{|l|}{ Education } \\
\hline Primary school or less & 1.00 & & 1.00 & \\
\hline College graduate & $1.14(0.83-1.56)$ & 0.395 & $0.61(0.40-0.94)$ & 0.257 \\
\hline Some graduate & $0.95(0.74-1.21)$ & 0.565 & $0.55(0.28-1.05)$ & 0.072 \\
\hline \multicolumn{5}{|l|}{ Income per year } \\
\hline$>\$ 50,000$ & 1.00 & & 1.00 & \\
\hline$<\$ 50,000$ & $1.93(1.50-2.48)$ & $<.0001$ & $3.82(2.25-6.51)$ & $<.0001$ \\
\hline \multicolumn{5}{|l|}{ Marital status } \\
\hline Married & 1.00 & & 1.00 & \\
\hline Unmarried/divorced/widow & $1.36(0.92-2.00)$ & 0.113 & $2.19(1.33-3.62)$ & 0.002 \\
\hline \multicolumn{5}{|l|}{ Smoking status } \\
\hline Nonsmoker & 1.00 & & 1.00 & \\
\hline Current or former smoker & $1.58(1.00-2.50)$ & 0.049 & $1.43(0.89-2.32)$ & 0.139 \\
\hline \multicolumn{5}{|l|}{ Household composition } \\
\hline Single & 1.00 & & 1.00 & \\
\hline With others & $0.99(0.66-1.49)$ & 0.984 & $1.31(0.82-2.01)$ & 0.255 \\
\hline \multicolumn{5}{|l|}{ Body mass index (BMI), kg/m² } \\
\hline Normal weight (18.5-24.9) & 1.00 & & 1.00 & \\
\hline Overweight (25-29.9) & $0.92(0.70-1.22)$ & 0.580 & $0.62(0.31-1.21)$ & 0.158 \\
\hline Obese $(\geq 30)$ & $0.99(0.74-1.32)$ & 0.946 & $0.97(0.53-1.79)$ & 0.923 \\
\hline
\end{tabular}

\section{Discussion}

The current study aimed to evaluate $\mathrm{HC}$ access in American minorities with or at high risk for knee OA compared to Caucasians with the same condition. In line with the hypothesis, American minorities had more insufficient access to HC than did Caucasians. The majority of older American minorities were less likely to have both HCC and insurance for access to HC than were Caucasians of a similar age. Compared to Caucasians, American minorities who had both $\mathrm{HCC}$ and insurance for access to $\mathrm{HC}$ had a lower level of education and annual income; although fewer American minorities were married or living with a 
family member, most were current smokers or obese. Concerning access to HC, Caucasians with HCC were more likely to use a private doctor, whereas American minorities with no HCC were more likely to visit a private doctor and private clinic followed by the emergency room and "other" options.

Our findings are among the first to provide evidence of access to $\mathrm{HC}$ in explaining racial differences in persons with or at high risk for knee $\mathrm{OA}$ above and beyond socioeconomic, lifestyle, and clinical factors. Several studies have explored possible explanations for racial and ethnic differences in access to HC [1, $14,17,19-24]$. A previous study found that access to HC can be explained according to the presence or absence of HCC [25]. Our study incorporated a broader definition of access to $\mathrm{HC}$, which is supported by research demonstrating that the presence of $\mathrm{HCC}$ and insurance is associated with the improved timely receipt of $\mathrm{HC}[26,27]$.

Access to $\mathrm{HC}$ in Caucasians and American minorities has been associated with different age groups, education, annual income, household composition, marital, and current smoking status in persons with or at high risk for knee OA. The findings of this study showed that persons aged 65 years and above had both HCC and insurance irrespective of race and ethnicity. Among Caucasians, access to HC was associated with higher education and annual income and fewer current smokers than among American minorities. The findings of the current study are similar to those of Dominick and Baker [28], who suggested that "American minorities (African Americans, Asians, and other non-whites) were at risk for poorer HC or poorly understood compared to Caucasians with OA". It has been well established that age, having a lower income and education, and an uninsured status limits the access to HC in American minorities compared to Caucasians $[11,17,29-32]$. The current study's findings that demonstrate a more indigent association with access to HC among American minorities support this hypothesis.

Racial and ethnic differences in the presence of access to $\mathrm{HC}$ may have contributed to our findings on those with or at high risk for knee OA. Results from the present study showed that American minorities were less likely to have HCC or a usual source of HC. American minorities with no HCC were likely utilizing a different source of access to $\mathrm{HC}$. In addition, the distribution of the types of routine care significantly differed between Caucasians and American minorities. Therefore, disparities in the quality of care were possibly more influential than the absence of usual care in persons with or at high risk for knee OA. For example, American minorities were less likely to have $\mathrm{HCC}$ or insurance and report seeing a private doctor than were Caucasians even among those with $\mathrm{HCC}$. These results are consistent with the findings on access to $\mathrm{HC}$ in other studies [33-37]. However, findings from the National Health Interview Survey (NHIS) showed that the uninsured status decreased from 2013 to 2014 among all race/ethnic groups aged 18-64 years in the United States [38]. According to the NHIS's findings, the changes in the percentage of uninsured individuals between 2013 and 2014 are Hispanics 41.1-34.1\%, non-Hispanic whites 14.5-11.5\%, non-Hispanic blacks 24.7-17.6\%, and non-Hispanic Asians 16.1-12.1\%.

\section{Strengths and limitations}

The present study has several strengths. To our knowledge, it is the first to evaluate access to $\mathrm{HC}$ in American minorities with or at high risk for knee OA in comparison to Caucasians using well-established and validated measures of HCC, insurance, and the usual source of HC. The results of the current study provide significant evidence regarding the influences of access to $\mathrm{HC}$ in explaining Caucasians and American minorities with or at high risk for knee OA. This article was prepared to utilize data from a publicly and privately funded large, multicenter prospective longitudinal study (OAI) that examines the onset or at high risk of knee OA. Considering the effects of $\mathrm{HCC}$ and insurance on the access to HC outcomes is unique and contributes to a broader understanding of persons with onset or at high risk of knee OA. In addition to the big sample size, data were used in this study came from the four clinical sites across the country. Therefore, the results of this study are generalizable to this population in the whole country.

The limitations of the present study included the cross-sectional design, which hinders comparisons between data over time or prevents establishing causality. The self-report nature of the critical variables-HCC and insurance- might decrease the generalizability of the current findings. The present study participants with onset or at high risk of knee OA were not representative of a person's onset or those at high risk of knee OA in the US general population. Access to $\mathrm{HC}$ among this study's participants differed from that of the United States' general population. These differences may reflect temporal changes in $\mathrm{HC}$ that occurred after the OAI baseline data was collected and may limit the generalizability of these findings. Further research will be needed to assess recent changes in a health insurance policy in the US by race and ethnicity-based on the onset or at high risk for knee OA. However, it is also possible that the participants' level of access to HC may have changed during follow-up, possibly introducing a misclassification bias. Another limitation, we were not performed a sub-cohort analysis between the cohorts (established and high risk for knee OA) to see the race/ethnicity difference in access to HC.

Recommendations of the expert committee from the IOM Access Monitoring Project should be implemented through policy to improve the state of measuring access problems in Americans with or at high risk for knee OA at both national and regional levels. ${ }^{1}$ Specialized surveys should focus on minorities to accomplish the implementation of policy in populations with knee OA status. In this survey, factors that play an important role other than the lack of HCC and insurance should be explained to identify the disparities in access to HC. HCC, to a great extent, is a good proxy for access, and insurance plays a role in influencing not only $\mathrm{HC}$ use but also outcomes. A well-established survey at the national and regional levels is required to flesh out these relationships.

\section{Conclusion}

American minorities had insufficient access to HC than did Caucasians. In American minorities, sociodemographic factors such as age, education, annual income, household composition, and marital and smoking statuses were influenced by lower access to HC even if individuals had both HCC and insurance. Most of the uninsured American minorities with no HCC were more likely to visit private doctors followed by the emergency room and "other" options to access $\mathrm{HC}$. The research will need to continue documenting racial and ethnic variation in access to $\mathrm{HC}$ to better inform policymakers and $\mathrm{HC}$ professionals for a solution that would allow American minorities with or at high risk for knee OA to access HC. Further studies are also needed to determine what types of differences in HCC ([such as Blue Cross], prepaid plans [such as HMOs], PPOs or any government-sponsored programs, such as Medicare, Medicaid, or VA 
coverage), insurance (e.g., part or full prescription medication coverage) and source of care (e.g. private doctor, public clinic, HMO, etc.) most strongly impact persons with or at high risk for knee OA.

\section{Abbreviations}

OA

osteoarthritis

$\mathrm{HC}$

health care

IOM

institute of medicine

HCC

health care coverage

TKA

total knee arthroplasty

OAI

osteoarthritis initiative

HMO

health maintenance organization

VA

veteran affairs

PPO

preferred provider organizations

US

United States

BMI

body mass index

SAS

statistical analysis software

NHIS

National Health Interview Survey

\section{Declarations}

Ethics approval and consent to participate

The study has been performed as per the Declaration of Helsinki. The Institutional Review Board of the University of California, San Francisco, and its affiliates approved the study. Written informed consent was obtained from individual participants before enrollment into the study.

\section{Consent for publication}

Not Applicable.

\section{Availability of data and materials}

The datasets generated and/or analyzed during the current study are publicly available in the National Institutes of Health repository, https://oai.nih.gov.

\section{Competing interests}

The authors declare that they have no competing interests.

\section{Funding}

The OAl is a public-private partnership comprised of five contracts (N01-AR-2-2258; N01-AR-2-2259; N01-AR-2-2260; N01-AR-2-2261; N01-AR-2-2262) funded by the National Institutes of Health, a branch of the Department of Health and Human Services, and conducted by the OAI Study Investigators. Private funding partners include Merck Research Laboratories; Novartis Pharmaceuticals Corporation, GlaxoSmithKline; and Pfizer, Inc. The Foundation for the National Institutes of Health manages private-sector funding for the OAI. This manuscript was prepared using an OAI public use data set and does not necessarily reflect the opinions or views of the OAl investigators, the $\mathrm{NIH}$, or the private funding partners. The author(s) received financial support for the research, authorship, and/or publication of this article from the Deanship of Scientific Research, King Saud University, through Research Group No. RG-1438085. The funding bodies played no role in the design of this study and collection, analysis, and interpretation of the data, in writing the manuscript, or the decision to submit the manuscript for publication. 
Conceptualization: VV, SMB Data curation: VV, SMB Formal analysis: VV Funding acquisition: SMB Investigation: VV, SMB Methodology: VV, SMB, TAA Project administration: SMB Resources: SMB Supervision: SMB Validation: VV, AMA Writing \pm original draft: VV Writing \pm review \& editing: VV, SMB, TAA, AMA. The author(s) read and approved the final manuscript.

Not Applicable.

\section{Authors' information}

Department of Rehabilitation Sciences, College of Applied Medical Sciences, King Saud University, Riyadh, 10219, Saudi Arabia

Vishal Vennu \& Saad M. Bindawas

Department of Basic Medical Sciences, Vision Colleges, Riyadh, Saudi Arabia

Tariq A. Abdulrahman

Department of Rehabilitation Sciences and Physical Therapy, Prince Sattam Bin Abdulaziz University, Alkharj, Saudi Arabia

Aqeel M. Alenazi

\section{References}

1. Millman M. Access to Health Care in America. Access to Health Care in America. Washington (DC): USA: National Academies Press (US); 1993.

2. Ma VY, Chan L, Carruthers KJ. Incidence, prevalence, costs, and impact on disability of common conditions requiring rehabilitation in the United States: stroke, spinal cord injury, traumatic brain injury, multiple sclerosis, osteoarthritis, rheumatoid arthritis, limb loss, and back pain. Archives of physical medicine and rehabilitation. 2014;95:986-995. e981.

3. Deshpande BR, Katz JN, Solomon DH, Yelin EH, Hunter DJ, Messier SP et al. Number of persons with symptomatic knee osteoarthritis in the US: impact of race and ethnicity, age, sex, and obesity. Arthritis care \& research. 2016;68:1743-1750.

4. Yelin E, Weinstein S, King T, editors. The burden of musculoskeletal diseases in the United States. Seminars in arthritis and rheumatism; 2016.

5. Losina E, Paltiel AD, Weinstein AM, Yelin E, Hunter DJ, Chen SP et al. Lifetime medical costs of knee osteoarthritis management in the United States: impact of extending indications for total knee arthroplasty. Arthritis care \& research. 2015;67:203-215.

6. Daigle ME, Weinstein AM, Katz JN, Losina E. The cost-effectiveness of total joint arthroplasty: a systematic review of published literature. Best practice \& research Clinical rheumatology. 2012;26:649-658.

7. BohI DD, Ondeck NT, Basques BA, Levine BR, Grauer JN. What is the timing of general health adverse events that occur after total joint arthroplasty? Clinical Orthopaedics and Related Research®. 2017;475:2952-2959.

8. Skinner J, Weinstein JN, Sporer SM, Wennberg JE. Racial, ethnic, and geographic disparities in rates of knee arthroplasty among Medicare patients. New England Journal of Medicine. 2003;349:1350-1359.

9. Huntington W, Covington L, Center P, Manchikanti L. Patient Protection and Affordable Care Act of 2010: reforming the health care reform for the new decade. Pain physician. 2011;14:E35-E67.

10. Schroeder SA. We can do better-improving the health of the American people. New England Journal of Medicine. 2007;357:1221-1228.

11. Wang TF, Shi L, Nie X, Zhu J. Race/ethnicity, insurance, income and access to care: the influence of health status. Int J Equity Health. $2013 ; 12: 29$.

12. Andersen RM, Davidson PL, Baumeister SE. Improving access to care. Changing the US health care system: key issues in health services policy and management San Francisco: Jossey-Bass. 2014:33-69.

13. Ayanian JZ, Weissman JS, Schneider EC, Ginsburg JA, Zaslavsky AM. Unmet health needs of uninsured adults in the United States. Jama. 2000;284:2061-2069.

14. Lillie-Blanton M, Hoffman C. The role of health insurance coverage in reducing racial/ethnic disparities in health care. Health affairs. 2005;24:398-408.

15. Fawaz-Estrup F. The osteoarthritis initiative: an overview. Med Health R I. 2004;87:169-171.

16. Li C, Dick AW, Fiscella K, Conwell Y, Friedman B. Effect of usual source of care on depression among Medicare beneficiaries: an application of a simultaneous-equations model. Health Serv Res. 2011;46:1059-1081.

17. Evans K, Coresh J, Bash LD, Gary-Webb T, Kottgen A, Carson K et al. Race differences in access to health care and disparities in incident chronic kidney disease in the US. Nephrol Dial Transplant. 2011;26:899-908.

18. Fact sheet 311: Obesity and overweight: World Health Organization; 2011 [Available rom: URL].

19. Burgos-Vargas R, Cardiel MH, Loyola-Sanchez A, De Abreu MM, Pons-Estel BA, Rossignol M et al. Characterization of Knee Osteoarthritis in Latin America. A Comparative Analysis of Clinical and Health Care Utilization in Argentina, Brazil, and Mexico. Reumatol Clin. 2013.

20. Caldwell JT, Ford CL, Wallace SP, Wang MC, Takahashi LM. Intersection of Living in a Rural Versus Urban Area and Race/Ethnicity in Explaining Access to Health Care in the United States. Am J Public Health. 2016;106:1463-1469.

21. Doherty E, O'Neill C. Estimating the health-care usage associated with osteoarthritis and rheumatoid arthritis in an older adult population in Ireland. J Public Health (Oxf). 2013. 
22. Karsdal MA, Christiansen C, Ladel C, Henriksen K, Kraus VB, Bay-Jensen AC. Osteoarthritis - a case for personalized health care? Osteoarthritis Cartilage. 2014;22:7-16.

23. Richardson LD, Norris M. Access to health and health care: how race and ethnicity matter. Mt Sinai J Med. 2010;77:166-177.

24. Sperber NR, Bosworth HB, Coffman CJ, Lindquist JH, Oddone EZ, Weinberger M et al. Differences in osteoarthritis self-management support intervention outcomes according to race and health literacy. Health Educ Res. 2013;28:502-511.

25. Hoogeboom TJ, Snijders GF, Cats HA, de Bie RA, Bierma-Zeinstra SM, van den Hoogen FH et al. Prevalence and predictors of health care use in patients with early hip or knee osteoarthritis: two-year follow-up data from the CHECK cohort. Osteoarthritis Cartilage. 2012;20:525-531.

26. Davis K, Abrams M, Stremikis K. How the Affordable Care Act will strengthen the nation's primary care foundation. J Gen Intern Med. 2011;26:12011203.

27. Ricketts TC, 3rd. How the Affordable Care Act will affect access to health care in North Carolina. N C Med J. 2013;74:324-329.

28. Dominick KL, Baker TA. Racial and ethnic differences in osteoarthritis: prevalence, outcomes, and medical care. Ethn Dis. 2004;14:558-566.

29. Lebrun LA, Shi L. Nativity status and access to care in Canada and the U.S.: factoring in the roles of race/ethnicity and socioeconomic status. J Health Care Poor Underserved. 2011;22:1075-1100.

30. Shi L, Lebrun LA, Tsai J. Access to medical care, dental care, and prescription drugs: the roles of race/ethnicity, health insurance, and income. South Med J. 2010;103:509-516.

31. Towne SD, Probst JC, Hardin JW, Bell BA, Glover S. Health \& access to care among working-age lower income adults in the Great Recession: Disparities across race and ethnicity and geospatial factors. Soc Sci Med. 2017;182:30-44.

32. Waidmann TA, Rajan S. Race and ethnic disparities in health care access and utilization: an examination of state variation. Med Care Res Rev. 2000;57 Suppl 1:55-84.

33. Cook BL. Effect of Medicaid Managed Care on racial disparities in health care access. Health Serv Res. 2007;42:124-145.

34. Cossman J, James W, Wolf JK. The differential effects of rural health care access on race-specific mortality. SSM Popul Health. 2017;3:618-623.

35. Hargraves JL, Hadley J. The contribution of insurance coverage and community resources to reducing racial/ethnic disparities in access to care. Health Serv Res. 2003;38:809-829.

36. Lopez JP, Burant CJ, Siminoff LA, Kwoh CK, Ibrahim SA. Patient perceptions of access to care and referrals to specialists: a comparison of AfricanAmerican and white older patients with knee and hip osteoarthritis. J Natl Med Assoc. 2005;97:667-673.

37. Wong MD, Asch SM, Andersen RM, Hays RD, Shapiro MF. Racial and ethnic differences in patients' preferences for initial care by specialists. Am J Med. 2004;116:613-620.

38. Martinez ME, Ward BW, Adams PF. Health Care Access and Utilization Among Adults Aged 18-64, by Race and Hispanic Origin: United States, 2013 and 2014. NCHS Data Brief. 2015:1-8.

\section{Figures}

\section{Figure 1: The flow of the study sample.}

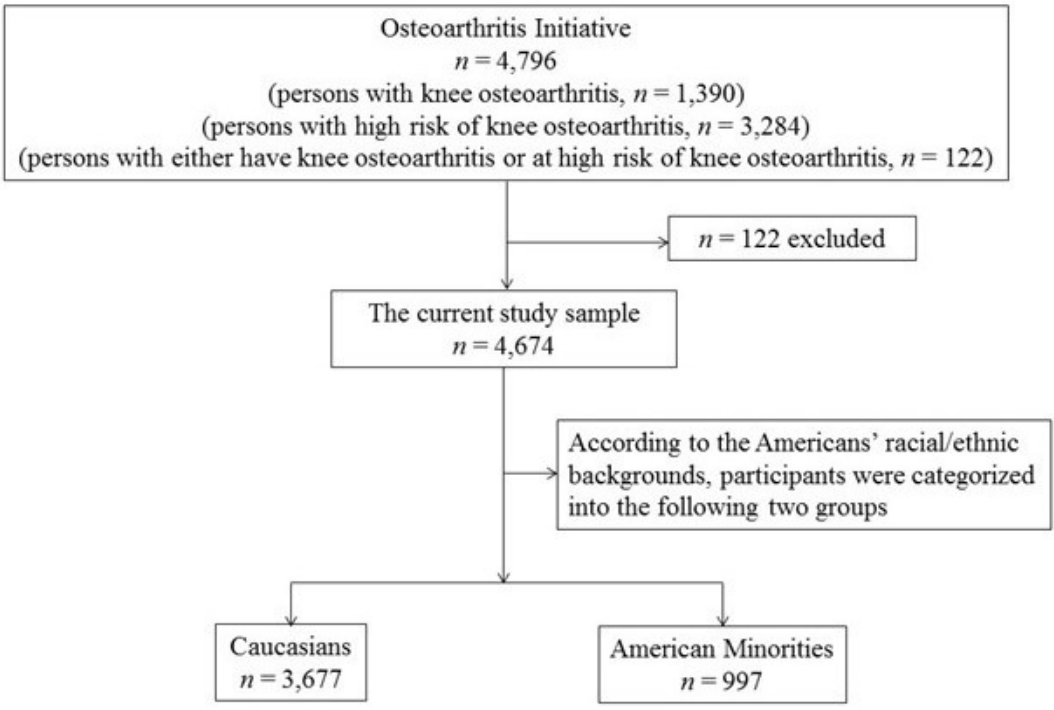

SOURCE Authors' analysis of baseline data from Osteoarthritis Initiative, 2004-6. NOTES The exhibit shows flow of the current study sample through the Osteoarthritis Initiative. The exhibit also presents the classification of participants according to their racial and ethnic background as Caucasians and American minorities.

Figure 1 
Figure 2: Self-reported (A) healthcare coverage and (B) no health care coverage in Caucasians and American minorities.
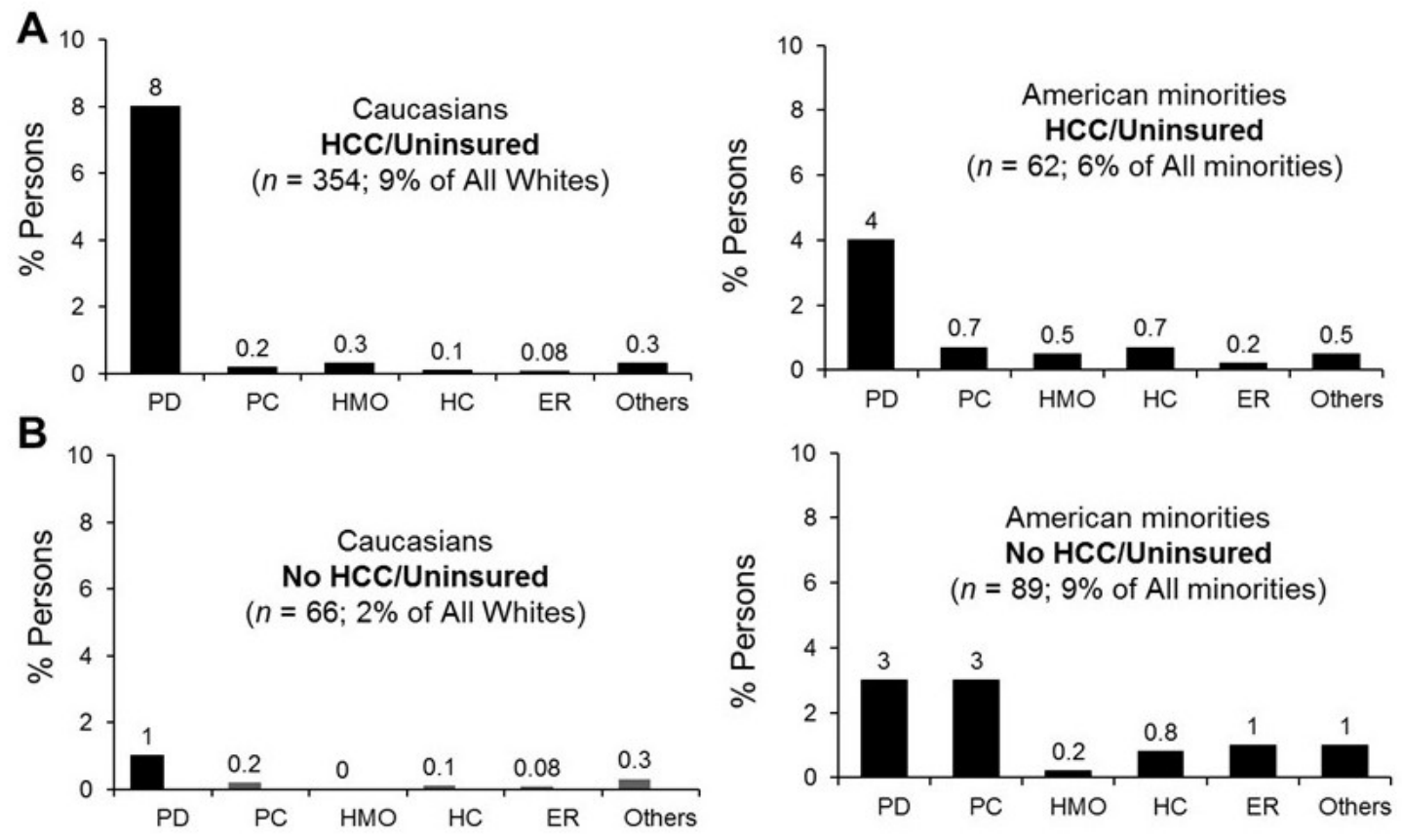

SOURCE Authors' analysis of baseline data from Osteoarthritis Initiative, 2004-6. NOTES The exhibit shows the status of HCC in Caucasians and American minorities. Both, but most Caucasians who had only HCC visited PD. However, majority American minorities who did not have both $\mathrm{HCC}$ and insurance visited both $\mathrm{PD}$ and $\mathrm{PC} . \mathrm{PD}=$ private doctor; $\mathrm{PC}=$ public clinic; $\mathrm{HMO}=$ health maintenance organization; $\mathrm{HC}=$ hospital clinic; $\mathrm{ER}=$ emergency room. $\mathrm{HCC}=$ health care coverage. Statistical significance between Caucasians and American minorities, $\mathrm{p}<.0001$.

\section{Figure 2}

See image above for figure legend 